\title{
The Influence of Internet on College Students' Mental Health
}

\author{
Zhang Meng, Wang Hong-wei*, Zhang Yuan-lin, Zhang Zi-han, Liu Ren-jie, Cao Zhi-han \\ College of Life Science, Hebei University, Baoding, China \\ Email:807569283@qq.com, 906472733@qq.com (corresponding author E-mail)*
}

\begin{abstract}
In recent years, with the development of network technology and the upgrading of mobile devices, the impact of Internet on college students has aroused widespread concern in society. This editorial sampled students from Hebei University to investigate students' use of the Internet, their understanding of the Internet, and their feelings about the Internet. Combined with previous research results of some scholars, the impact of the Internet on the psychological health of college students was explored.
\end{abstract}

\section{Keywords-Mental health; College students; Internet}

\section{INTRODUCTION}

Internet use has been interwoven into the fabric of our daily lives for various purposes. However, excessive Internet use can also be pathological and addictive, commonly referred to as "Internet addiction (IA)" [1]. In addition, it was suggested that, like patients with substance use disorder, excessive Internet users are affected by core symptoms of addictions, such as salience, tolerance and interpersonal barriers and so on. Further, as an addiction itself, IA could have detrimental effects on one's psychological health, especially in the presence of its commonly co-occurring psychiatric disorders, such as attentiondeficit/hyperactivity disorder (ADHD) and depression [2], which may further exacerbate psychological health [3-4] With the popularization of computers and networks in our country, a virtual network society may have a profound influence on the economic, political, and cultural fields in the real world.

Some studies have demonstrated harmful health effects of IA across different aspects of health. First, negative effects on physical health may add to some unhealthy lifestyles such as abnormal rest habits, bad habits, unhealthy diet, and lack of exercise, regular drinking and late-night Internet access. These habits will have a negative impact on the body of Internet addiction patients. Second, it is the impact on mental health. The mental health in our research means the health of certain aspects of human being such as intelligence, mind and thought. Studies have shown that the Internet addiction is one of the major factors influencing mental [5]. People with Internet addiction often show low learning efficiency, decreased work enthusiasm, listlessness, and reduced ability to respond.

College students are the backbone of social development and construction. Their mental health not only affects the overall development of their physical and mental health, but also affects the development and progress of the entire society.
In terms of psychological and ideological cognition, they are still in an incomplete stage of maturity. Ideas and behaviors need to be guided and consolidated. On the one hand, as social elites are praised by others, but they also carry high expectations of society and parents, and the pressures and problems they face are significantly higher than other peer groups. During the university period, they not only have to face issues from their studies but also face issues from the living environment, interpersonal relationships, career choices, and emotions. Some college students have shown discomfort and some have even experienced psychological problems. In recent years, the incidents of self-injury and campus violence among college students have shown an upward trend, which is worrying. On the other hand, the penetration of the Internet has penetrated into all aspects of students [6]. At the same time, various factors such as good and bad network information, high degree of freedom, and security pose serious challenges to the mental health of college students and their education.

\section{METHODOLOGY}

\section{A. Participant}

The scope of the study is for some undergraduates and postgraduates in 19 colleges of Hebei University, to conduct a sample survey of these students. The scope of the study is for some undergraduates and postgraduates in 19 colleges of Hebei University, to conduct a sample survey of these students. In this study, 400 questionnaires were distributed and 368 valid questionnaires were returned. The effective rate was $92 \%$. Among them, there were 88, 76, 79 and 64 students in the first to fourth grades. In addition, 61 graduate students also participated in our survey.

\section{B. Mental Health Questionnaire}

The design of the questionnaire refers to a number of books, documents and questionnaires related to the Internet and mental health of college students. The final completed questionnaire is divided into three parts. The first part is to understand the basic situation of the students. The second part is to understand the students' use of the Internet. The third part concerns the network security of college students. 


\section{RESULTS}

TABLE I THE TIME OF STUDENT USE INTERNET

\begin{tabular}{ccc}
\hline Duration & Number & Proportion \\
\hline $1-2$ hours & 27 & $7.34 \%$ \\
\hline $2-3$ hours & 95 & $25.76 \%$ \\
\hline $3-4$ hours & 135 & $36.72 \%$ \\
\hline Over4 hours & 111 & $30.18 \%$
\end{tabular}

As it was shown in table 1, more than $66 \%$ of students use the network for more than 3 hours. In addition, from the survey results, at least $88.56 \%$ of college students have computers, and there is an upward trend from grade one to graduate students. More than half of the students said that the time spent on the Internet was significantly higher than before. Even $17.14 \%$ of students admitted that they had skipped classes due to online games. Students, $51.49 \%$ of total survey, they said that because of the internet, part of the group activities and outdoor sports were abandoned. And $58.21 \%$ of students felt physically and mentally exhausted because of the Internet, however they still chose to sit at the computer. About $20.67 \%$ of students said that they sometimes get addicted to the Internet, but they will deliberately stop. And $10.77 \%$ of students said that they may be delayed due to the Internet. About $10.35 \%$ of students said they did not plan and manage the time of the Internet. Although from the perspective of use, students spend a considerable part of their time learning and working with the Internet and expanding their interaction space. However, some students still use the Internet irrationally, causing the Internet to bring them adverse effects such as dependence, internet addiction, abandoned studies and procrastination.

TABLE II THE CREDIBILITY OF NETWORK INFORMATION

\begin{tabular}{ccc}
\hline Trust level & Number & Proportion \\
\hline Mostly trusted or Less credible & 111 & $30.28 \%$ \\
\hline Partly trusted & 220 & $59.90 \%$ \\
\hline Less credible or untrustworthy & 37 & $9.82 \%$ \\
\hline
\end{tabular}

As it was shown in table 2, most students now believe the information described on the web. According to the survey conducted by our university, there are $30.28 \%$ of students are convinced of the information on the Internet. And $59.90 \%$ of students believe that something on the Internet can only be trusted, but not all. Only $9.82 \%$ of students believe that something on the Internet is false and that they can't believe it. As previously described by the relevant research institutes, Survey shows $15.6 \%$ of university students fully agree that "the Internet can reflect the real world," and about $50.9 \%$ of students "substantially agree." At the same time, the results show thatabout $33.9 \%$ of students often perceive information on the Internet as hype. Survey shows also show $47.7 \%$ of university students can identify some violent, pornographic, fraudulent and reactionary information on the Internet. The results show that except for a small part of the information coming from official websites such as government websites, about $53.61 \%$ of the students obtain information from sites such as Tencent and today's headlines. These websites are often lack of government supervision, and often have some information distorting the facts, in order to get higher traffic and get more profits.

TABLE III THE FREEDOM OF INTERNET SPEECH

\begin{tabular}{ccc}
\hline Degree of freedom & Number & Proportion \\
\hline Complete freedom & 48 & $12.98 \%$ \\
\hline Relatively free & 280 & $76.21 \%$ \\
\hline Restricted & 40 & $10.81 \%$
\end{tabular}

As it was shown in table 3, nearly $90 \%$ of students think they have great freedom of speech on the Internet. In a further survey, we found that about $66.47 \%$ of students are not familiar with Internet regulations. Survey shows $73.46 \%$ of students have published their true information on the Internet, including filling in employment information and registering accounts. A total of $5.49 \%$ of students said that they have been frequently violated by the Internet, such as spam, account theft, and network viruses. The data shows that $60.34 \%$ of students said that they are occasionally affected by the Internet. The diversified online world, using its high degree of openness and the curiosity of college students, can easily instill in the students unhealthy ways of thinking and values. Under a long period of time, it is easy to cause college students to have cognitive biases and rebellious psychological enhancement. Moreover, due to students generally lack awareness of network laws and network security, college students are often more vulnerable to Internet violations. 
TABLE IV MENTAL CHANGES AFTER LONG-TIME USE OF THE INTERNET

\begin{tabular}{cccccc}
\hline Participant & $\begin{array}{c}\text { Lack of } \\
\text { passion }\end{array}$ & A little lonely & Some lost & No change & Some helpless \\
\hline First grade & $12.18 \%$ & $17.63 \%$ & $8.32 \%$ & $55.66 \%$ & $6.21 \%$ \\
\hline Second grade & $10.34 \%$ & $8.12 \%$ & $6.41 \%$ & $73.72 \%$ & $1.41 \%$ \\
\hline Third grade & $11.79 \%$ & $12.46 \%$ & $6.77 \%$ & $66.19 \%$ & $2.79 \%$ \\
\hline Fourth grade & $24.67 \%$ & $13.82 \%$ & $7.33 \%$ & $50.77 \%$ & $3.41 \%$ \\
\hline Postgraduate & $8.32 \%$ & $14.32 \%$ & $5.31 \%$ & $69.68 \%$ & $2.37 \%$ \\
\hline Total & $13.46 \%$ & $13.27 \%$ & $6.83 \%$ & $63.20 \%$ & $3.24 \%$
\end{tabular}

As it was shown in table 4, a long period of online life will increase students' loneliness. Although $63.20 \%$ of people believe that the use of the Internet has no influence on their psychological status, about $37 \%$ of students still believe that a long period of online life brings them a sense of loneliness. As mentioned in previous studies, only $10 \%$ of the experimenters showed that the time for the Internet to allow them to participate in social networking became less [7]. Sanders's (2000) research on teenagers shows that the use of the Internet is negatively related to the relationship between parents and friends [8]. There are also some studies that show that because of indulging in online dating, they feel even lonelier.

TABLE V THE CHANNELS OF RESOLVE ANXIETY

\begin{tabular}{ccccc}
\hline Participant & $\begin{array}{c}\text { Communicate with } \\
\text { classmates }\end{array}$ & $\begin{array}{c}\text { Reading, listening to } \\
\text { music and so on }\end{array}$ & Internet surfing & $\begin{array}{c}\text { Ask the teacher, } \\
\text { parents for help }\end{array}$ \\
\hline First grade & $71.68 \%$ & $55.68 \%$ & $49.81 \%$ & $37.23 \%$ \\
\hline Second grade & $62.42 \%$ & $58.24 \%$ & $52.61 \%$ & $26.48 \%$ \\
\hline Third grade & $78.25 \%$ & $50.67 \%$ & $46.18 \%$ & $27.55 \%$ \\
\hline Fourth grade & $67.20 \%$ & $51.89 \%$ & $51.64 \%$ & $30.08 \%$ \\
\hline Postgraduate & $60.89 \%$ & $53.08 \%$ & $55.06 \%$ & $32.71 \%$ \\
\hline Total & $68.89 \%$ & $54.11 \%$ & $50.91 \%$ & $32.75 \%$ \\
\hline
\end{tabular}

As it was shown in table 5, When college students encounter pressures such as study, life, and employment, they will actively seek help from classmates, teachers, and parents. On the other hand, students often choose to read books, listen to music, and surf the Internet to relax. On the whole, a considerable number of students will relieve their stress through online life, including browsing news, watching videos and games. Whether it is from computers or mobile phone, the Internet has indeed played a role in relieving pressure on them. With the development of mobile phones, more and more students have disclosed their anxiety through their mobile Internet. Through the network as a medium, get more people's help and concern. Therefore, the correct use of the Internet will help improve the mental health of college students.

\section{DISCUSSION}

\section{A. Effects of Internet Addiction on Mental Health}

Numerous studies have demonstrated harmful health effects of IA across different aspects of health. First, physical health could be affected because IA was often associated with a number of unhealthy lifestyles, including poor diets, physical inactivity, drinking behavior [9], and late-night Internet use [10] As already mentioned, IA could have detrimental effects on one's psychological health, especially in the presence of its commonly co-occurring psychiatric disorders, such as attentiondeficit/hyperactivity disorder (ADHD) and depression[7]. Some studies have shown that online life may make people more hypocritical. A study showing that honesty has a negative effect on perceived online dating success [11]. Similarly, individuals who disclose negative aspects of themselves bear the risk of being disliked by others. In addition, IA has also been found to be related to lower life satisfaction with family, friends, school, and living environment[12], suggesting that IA could have adverse effects on the social and environmental aspects of health. And some studies have shown that addicting to online games could increase aggression levels of college students 
[13].However there is also an American scholar, Mark Colson, who points out that even if you play Call of Duty for seven hours a day, it maybe make you nervous, but you do not go rob.

Previous research surface of internet addiction is one of the major factors influencing mental and physical health. Related research shows that, there are fifty-eight percent of schoolchildren and students have experienced a significant reduction in study habits, grades drop, absence in the class, and so forth. Additionally, they will spend less time doing academic activities. Many countries have taken certain measures to control the negative influence of the Internet on the healthy life of college students. According to an editorial calling for more attention to IA and recommending its inclusion in the DSM-5, IA has been regarded as one of the most serious public health issues in South Korea, and China's government has even enacted laws to regulate adolescent Internet use behavior [14]. Notably, college students have been documented to be particularly vulnerable to IA, given their psychological and developmental characteristics of late adolescence and ready access to the Internet. With rapid advances in Internet technologies and high Internet penetration rates in China, there is reason to be concerned that IA may worsen in the college student population owing to their increasing dependence on the Internet for learning and social.

According to the results of this survey, it can be seen that excessive use of the Internet will affect the face-to-face communication between college students and others. This will undermine the psychological health of college students, specifically manifested as emotional indifference, social communication obstacles and so on. Under long-term effects, students will experience a decline in their sense of existence, a decrease in their sense of worth, and a lack of self-confidence and other negative emotions. The release of various kinds of information on the Internet, instilled in the minds of students, can interfere with the discernment of students on right and wrong. Due to the lack of awareness of network security, they are extremely vulnerable to cyber criminals in cyber life; even they may touch the legal bottom line.

\section{B. Effects of Internet Addiction on Physical Health}

Combined with this survey, it is easy to see that with the development of the Internet and the upgrading of mobile devices, college students are using the Internet for longer. The prolonged use of the Internet will inevitably reduce the extracurricular activities and physical exercise time of the students and will worsen their physical fitness. The use of computers takes too long and damages the shoulders and spine. Prolonged use of mobile phones tends to cause tendinitis, which can severely degenerate your fingers. Because of the network and the messy life, it interferes with the body's normal biological clock and causes endocrine disorders.

Due to going to bed later at night because of using the Internet, 43 percent of the students have faced with failure at school. Researcher studied the influence of Internet addiction on students; they found that because of excessive use of the Internet on third of these students have suffered from physical and psychological problems, happiness and positive thought reduction and academic problems. This is bad news. On university students found that people with the Internet addiction, they are easily tired and dejected. They are alone, bashful and shy, while having low quality of life and suffering from depression and other types of problems in Van Gelderresearch [15]. Thomson in a research on the effects of the Internet addiction on the feeling of lack of suitable and actual social relations among the students showed that lots of students have recorded that their social skills is impaired, such as vision obscurity, insomnia and so on. Therefore, the existence of Internet has brought some negative effects to college students.

\section{The Positive ImPaCt Of InTERnet On COLLEGE STUdents' Mental HeAlth}

However, proper and correct use of Internet can help college students to solve their negative emotions. Stiles's fever model of disclosure was generally supported by this study, suggesting that stressful life events motivated self-disclosure on social software [16]. In particular, this study found that in times of stress individuals share greater amounts of intimate information and have more intentional disclosures on social software. This may be caused by the heightened negative emotions generated by stressful life events so intense that need to be shared. Furthermore, some study uncovered a stressbuffering effect of social software disclosure. Moderation analyses show that intentional disclosures moderate the stressdepression linkage, suggesting that deliberately sharing one's experiences and emotions helps decrease depressive symptoms in times of stress.

Moreover, the amount/intimacy, honesty, and intent of selfdisclosure were found to moderate the relationship between stressful life events and life satisfaction. When confronting stressful life events, individuals who made intimate and intentional disclosures on Facebook experienced increased life satisfaction. These findings are in line with existing evidence that people are likely to be healthier and happier if they talk about their problems with others [17], presumably because of the catharsis effect that expressing one's concerns makes a person feel unburdened and relieved [16].

\section{SUMMARY}

Therefore, combined with the research results of other researchers, it can be seen that in recent years, with the development of network technology and the upgrading of mobile devices, the frequency of college students' Internet access has increased significantly, and the time has become significantly longer. This has made the impact of the Internet on the mental health of university students even greater. Of course, this impact has not only negative but also positive effects.

The negative impact is mainly reflected in the long period of indulging in the network will make students' social ability drop, self-cognition ability decline, discrimination of right and wrong ability, existential value weakening and so on. The positive effect is reflected in the fact that the developed network can provide students with richer help and help students communicate with others. Students can express their anxiety through the Internet, so they can get a soothing mood and help ease the anxiety and stress of students in their studies and life. Therefore, the correct use of the Internet and the strict control 
of the time spent on the Internet will contribute to the development of the mental health of contemporary college students.

\section{ACKNOWLEDGMENT}

*Projects of biological science comprehensive reform pilot in teaching quality construction (2012-6).

\section{REFERENCES}

[1] Widyanto, L., \& Griffiths, M. (2006). 'Internet addiction': A critical review. International Journal of Mental Health and Addiction, 4(1), 31 51.

[2] Ko, C. H. (2008). Psychiatric comorbidity of internet addiction in college students: An interview study. CNS Spectrums, 13(2), 147-153.

[3] Ciarrochi, J., et al. (2016). The development of compulsive internet use and mental health: A four-year study of adolescence. Developmental Psychology, 52(2), 272-283.

[4] Muusses, L. D., et al. (2014). A longitudinal study of the association between Compulsive Internet use and wellbeing. Computers in Human Behavior, 36, 21-28.

[5] Chern K C, Huang J H. Internet addiction: Associated with lower healthrelated quality of life among college students in Taiwan, and in what aspects [J]. Computers in Human Behavior, 2018.

[6] R.J. Fleischmanna, M. Harrera, A.-C. Zarskia, H (2018). Patients experiences in a guided Internet- and App-based stress intervention for college students: A qualitative study. Internet Interventions. 12.001.

[7] Morahan-Martin J, Schumacher P .2003.Loneliness and social uses of the internet. Computers in Human Behavior (6):659-671.

[8] Sanders C, Field T, Diego M, et al.2000. The relationship of internet use to depression and social isolation among adolescence. Adolescence, $35: 237-242$

[9] Lam, L. T., et al. (2009). Factors associated with Internet addiction among adolescents. CyberPsychological \& Behavior, 12(5), 551-555.

[10] Ceyhan, A. A. (2008). Predictors of problematic Internet use on Turkish university students. CyberPsychology \& Behavior, 11(3), 363-366.

[11] Winer, D. L., Bonner, T. O., Jr., Blaney, P. H., \& Murray, E. J. (1981). Depression and social attraction. Motivation and Emotion, 5(2), 153-166.

[12] Cao, H., et al. (2011). Problematic Internet use in Chinese adolescents and its relation to psychosomatic symptoms and life satisfaction. BMC Public Health, 11, 802.

[13] Mohammadi, A. (2003). Advantages of computer games. Effects of computer games on children and adolescents.

[14] Block, J. J. (2008). Issues for DSM-V: Internet addiction. American Journal of Psychiatry, 165(3), 306-307.

[15] Van Gelder, T. (2005). Teaching critical thinking: some lessons from cognitive science. College Teaching, 45, 1-6.

[16] Stiles, W. B. (1987). "I have to talk to somebody": A fever model of disclosure. In V. J. Derlaga, \& J. H. Berg (Eds.), Self-disclosure: Theory, research and therapy (257-282). New York, NY: Plenum Press.

[17] Coates, D., Wortman, C. B., \& Abbey, A. (1979). Reactions to victims. New Approaches to Social Problems, 12(3), 21-52. 